
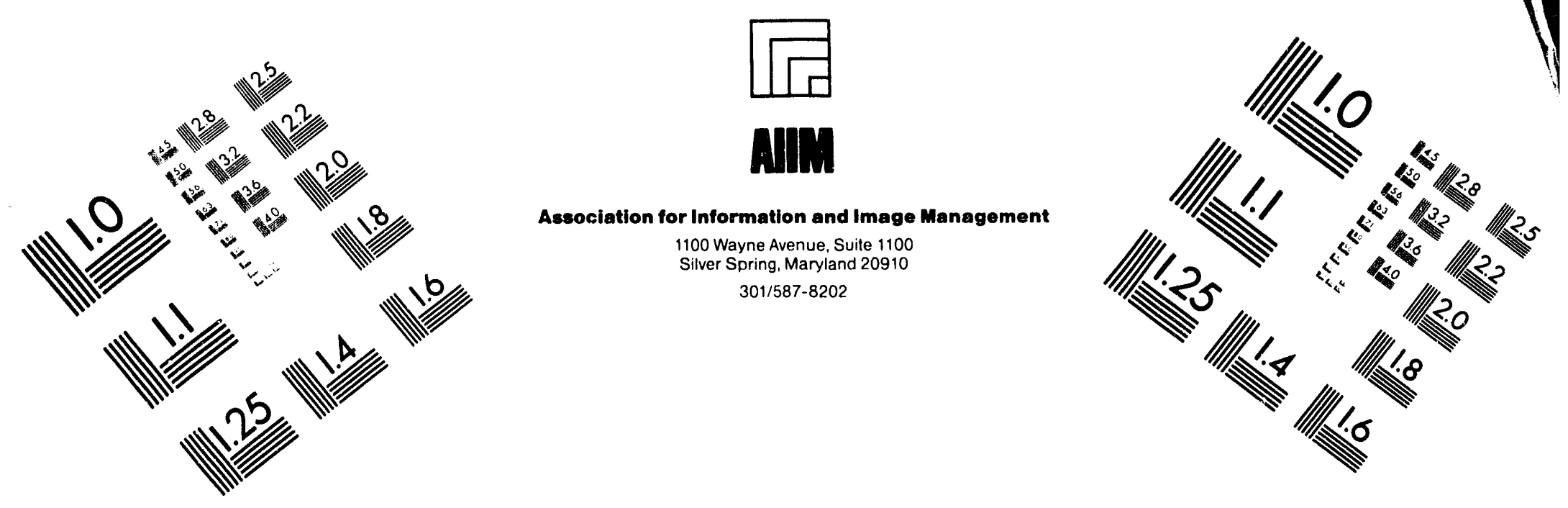

\title{
Centimeter
}

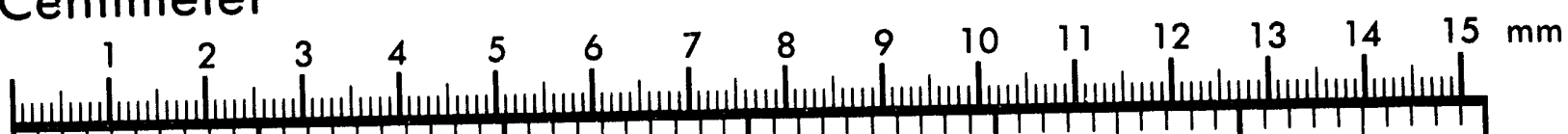

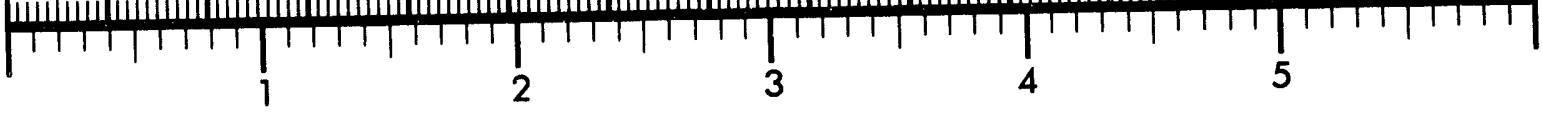
Inches
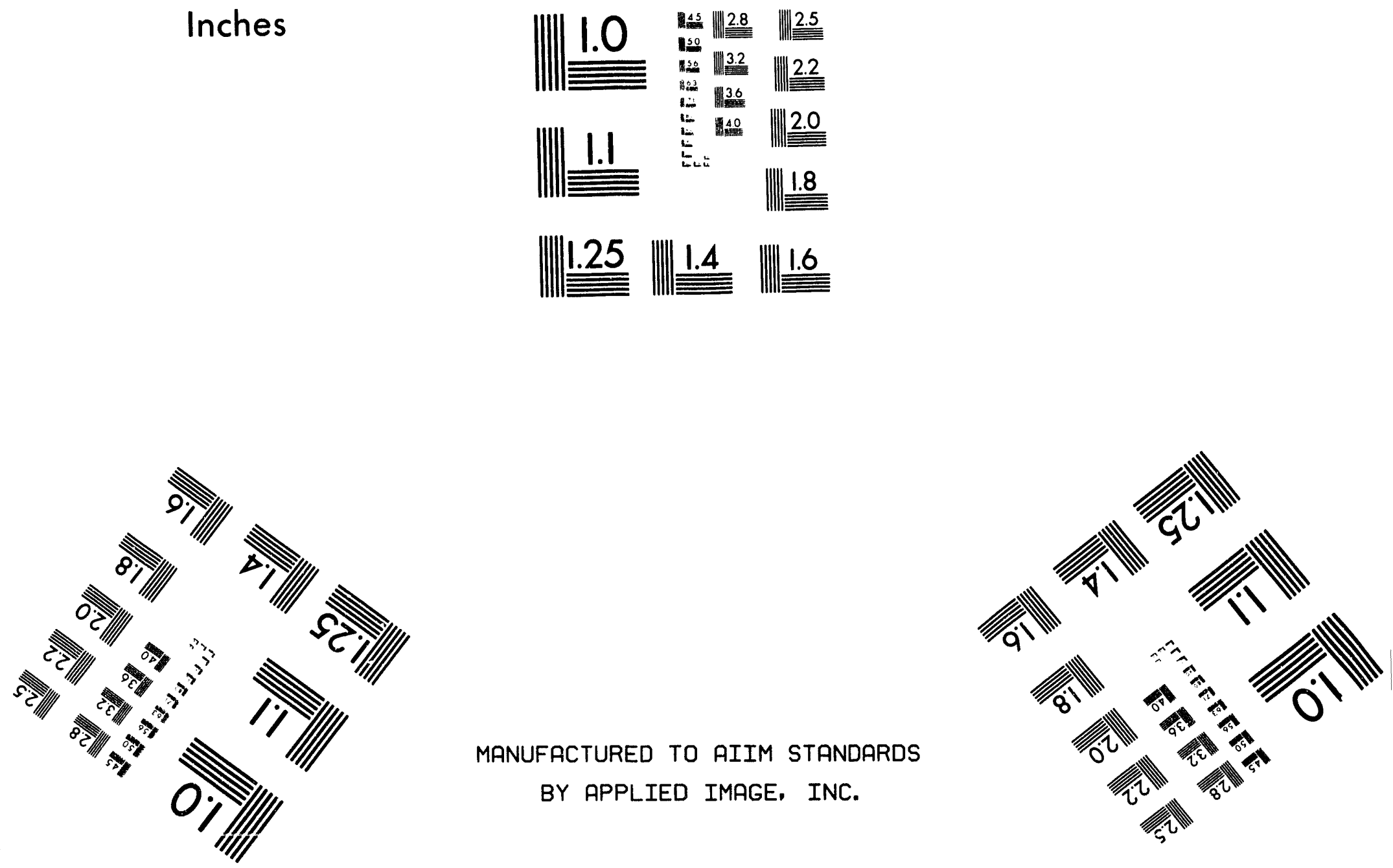

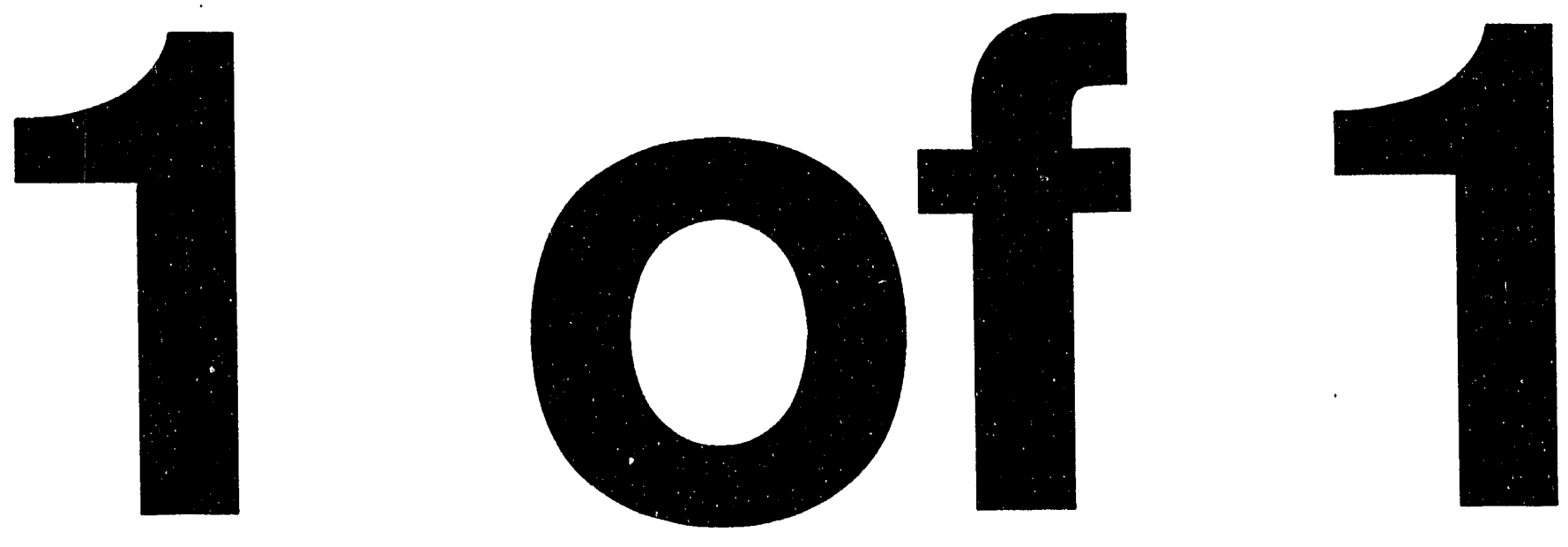
LA-UR- 93-2292

\section{Title: OMEGA PHASE FORMATION IN SHOCK-LOADED ZIRCONIUM}

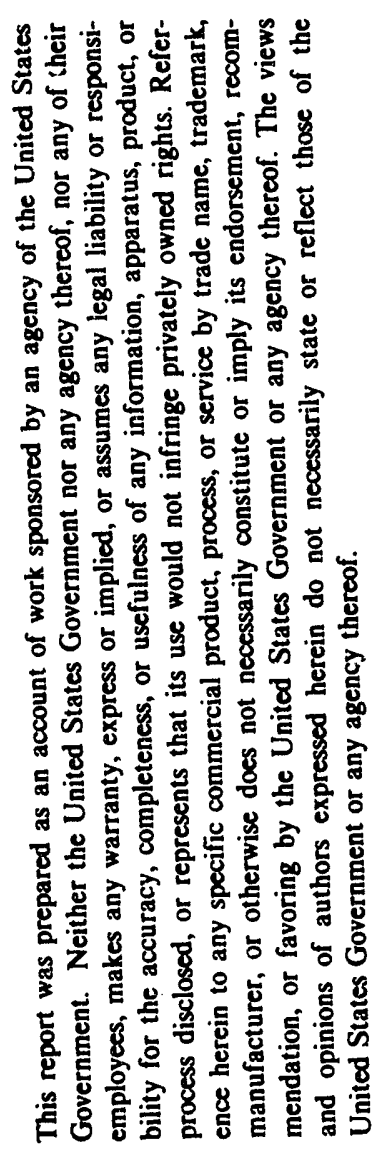

Author(s):

\section{Submitted to:}

\section{S. Song and G. T. Gray III}

\section{APS Topical Conference on Condensed Matter June 28 - July 2, 1993 Colorado Springs, $\mathbf{C O}$}

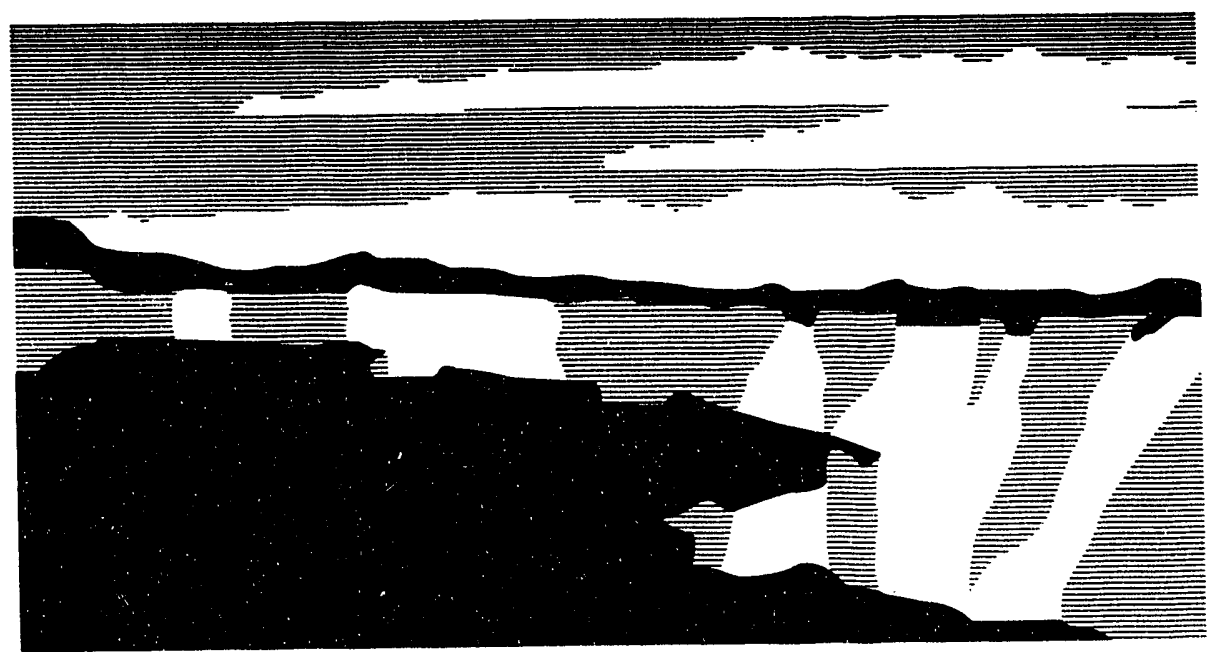

Los Alames National Laboratory, an affirmative actionequal opportunity empldyer, is operated by the University of California for the U.S. Department of Energy under publish or reproduce the published form of this contribution, or to allow others to do so, for U.S. Government purposes. The Los Alamos National Laboratory publish or reproduce the published form of this contribution, or to allow others to do so, 


\title{
Omega Phase Formation in Shock-Loaded Zirconium
}

\author{
Shihong Song and George T. Gray III \\ Los Alamos National Laboratory, Los Alamos, NM 87545
}

\begin{abstract}
$\Lambda$ shock recovery experiment and post-shock mechanical measurements were conducted on high-purity $\mathrm{Zr}$. Mechanical properties of the $\mathrm{Zr}$ samples before and after the shock loading are compared and discussed in terms of the substructure evolution during the shock loading. Metastable $\omega$-phase was found in the $\mathrm{Zr}$ sample following shock-loading to $7 \mathrm{GPa}$. A new orientation relationship between the $\alpha$ and $\omega$ phases was derived which does not agree with those previously reported in hydrostatic pressure experiments. A mechanism is proposed for the observed $\alpha \rightarrow \omega$ transformation.
\end{abstract}

\section{Introduction}

The pressure-induced phase transformation in $\mathrm{Ti}$ and $\mathrm{Zr}$ was first reported by Bridgman [1] as a result of his hydrostatic pressure studies of these materials. The nature of this transition was not clear until Jamieson [2] identified the new phase to be the w-phase whose structure had already been established in $\mathrm{Ti}$ and $\mathrm{Zr}$ alloys. Since then, an intensive effort has been made to investigate the kinetics, crystallography, and electronic structure variation of this $\alpha \rightarrow \omega$ transition under high hydrostatic and dynamic pressures.

Although the existence of the pressure-induced $\alpha \rightarrow \omega$ phase transformation in $\mathrm{Ti}, \mathrm{Zr}$, and $\mathrm{Hf}$ is well established, limited experimental data exists concerning the structure/property relationships of zirconium subjected to shock loading. Crystallographically, one of the fundamental problems concerning the transformation, i.e., the orientation relationship (OR) between the $\alpha$ - and $\omega$ phases in $\mathrm{Ti}$ and $\mathrm{Zr}$ remains a controversial issue. The $\alpha-$ $\omega$ OR was first studied by Sargent and Conrad in pressure-treated pure $\mathrm{Ti}$ and it was found to be $(0001)_{\alpha} / /$

$(1120)_{\omega}$ and $[1120]_{\alpha} / /[2201]_{\omega}$ [3]. A later study by Usikov and Zilbershtein [4] found that the OR of $(0001)_{\alpha}$

$/ /(1101)_{\omega}$ and $[2110]_{\alpha} / /[3033]_{\omega}$ was present in pressure treated pure $\mathrm{Ti}$ as well as $\mathrm{Zr}$ which, however, conflicts with the previous result. Moreover, Rabinkin et al. [5] studied the $\alpha \rightarrow \omega$ transition in pure $\mathrm{Zr}$ subjected to high pressure soaking up to $10 \mathrm{GPa}$ and obtained an OR similar to that reported by Sargent and Conrad in Ti but different from that reported earlier for $\mathrm{Zr}$ [4].

Reviewing the studies concerning the transformation, it appears that little effort has been made to describe the microstructural aspects of the process. It is commonly accepted that the $\alpha \rightarrow \omega$ transformation is of the martensitic (diffusionless) type [5,6,7]. Since this type of transformation involves a lattice reconstruction that occurs principally through homogeneous shearing plus a discrete amount of dilatation (or contraction), the crystallographic and microstructural aspects of the process are crucial in understanding its mechanism.

A new OR between the $\alpha$ and $\omega$ phases was observed in shock-loaded pure $\mathrm{Zr}$ in the present investigation which differs from those previously reported in $\mathrm{Zr}$ and $\mathrm{Ti}$. A detailed crystallographic and microstructural study using TEM was conducted in addition to the pre-and post-shock mechanical measurements at varjous strain rates and temperatures. Owing to the length restriction of the proceedings, only the main results and a brief discussion are presented here.

\section{Experimental}

High-purity crystal-bar zirconium containing < 50 ppm oxygen was shock-loaded to $7 \mathrm{GPa}$ and softrecovered using techniques described elsewhere [8]. Cylindrical specimens of $5 \mathrm{~mm}$ (height) $\times 5 \mathrm{~mm}$ (diameter) were machined from both the annealed starting material and the shock-loaded sample for post-shock measurements at different strain rates and temperatures. Samples for TEM examination were subsequently sliced, ground, and polished to a thickness of $100-150 \mathrm{~mm}$, then twin-jet polished in a perchloric (10\%) and methanol (90\%) solution until perforation. Thin film samples were examined using a Philips CM.30 transmission electron microscope operating at $3(0) \mathrm{kV}$.

\section{Results and Discussion Mechanical behavior}

Figure 1 shows the stress-strain response of the compressive tests on some of the pre- and post-shock $\mathrm{Zr}$ samples. The stress-strain curves are seen to contain two distinct regions in the plastic regime, i.e., a protracted

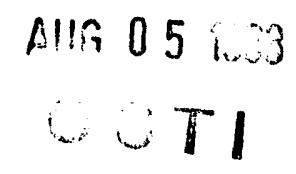


idastic-plastic transition (Regime I), particularly in the annealed materials followed by a nearly linear hardening regime (Regime II). Close examination of the results, not all shown in Fig. 1, reveals that $i)$ the yield stress increases with strain rate and decreases with temperature in both the pre- and post-shock samples and the yicld stress of the latler is about $60 \%$ higher than that of the cinmer; ii) the decrease of the initial work hardening rate in Regime I is laster in tests of higher strain rate in the me-shock samples and it is insignificant in the post-shock samples; iii) in contrast with the post-shock sample selormed at $76 \mathrm{~K}$, a very rapid elastic-plastic transition to a nearly constant hardening rate is seen in the curve of the pri-shock sample tested under the same conditions.

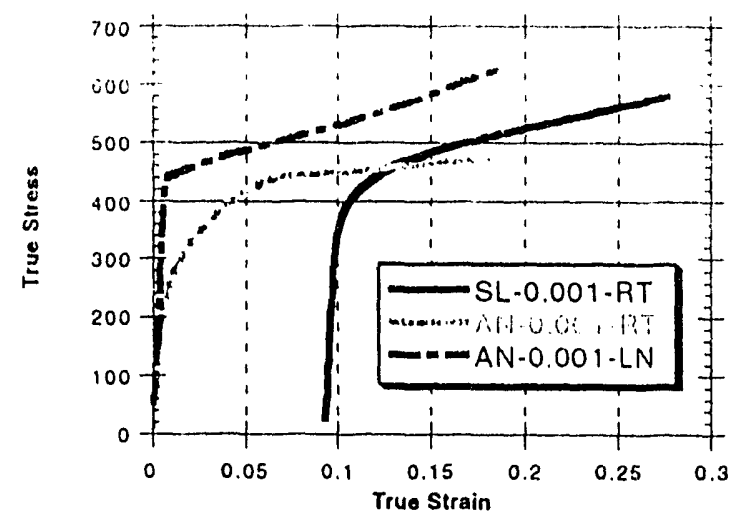

Figure. 1 Stress-strain response of the annealed and shock-loaded $\mathrm{Zr}$ samples, (SL - shock-loaded, AN unnealed, LN - liquid nitrogen, RM - room temperature, and $0 .(001$ - strain rate).

\section{Microstructural examination}

The typical microstructure of the pre-shocked samples deformed to $20 \%$ strain at room temperature is shown in Fig. 2a. Besides the well-developed subgrain structure about half the grains are heavily twinned. All the twins observed in TEM examinations are of the (1102) type seen most frequently at room temperature in $\mathrm{Zr}[9,1(1)$. A much larger scale of twinning was seen in the samples delormed at $76 \mathrm{~K}$ and in the shock-loaded samples, Fig. 2b. In addition to the dominant twin, a fair amount of (1122) twinning was also detected. The most active slip system in matrix is $\langle 112(1\rangle\{1100\}$ system, consistent with previous studies on slip in $\operatorname{Zr}[11]$, however, $\langle(X)(0) 1\rangle$ $\{1 I(k)\}$ slip system was occasionally seen in some grains.
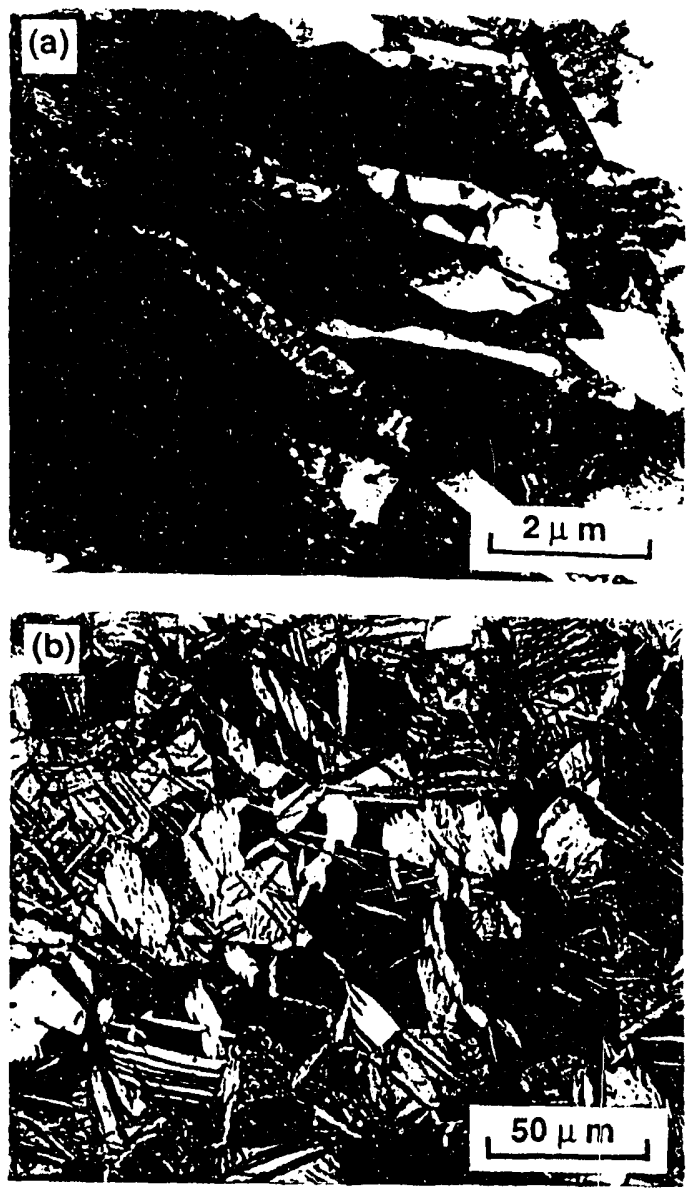

Figure 2 Typical microstructure of the samples deformed al room lemperature (a) and an optical micrograph of the sample deformed at $76 \mathrm{~K}$ (b).

The latter type dislocation, however, was frequently found within twins, the arigin of which is discussed elsewhere [12]. In addition to the high volume fraction of twins in the shock-loaded samples, well-developed microbands were frequently seen in the matrix.

Morphology of the wphase

Figures $3 a$ and $h$ show TEM bright and dark-lield micrographs of the retained w-phase in the shock-loaded samples. A large portion of the micrographs consists of the retained $\omega$-phase, with lattice constants $c=3.136$ and $a=5 .(1399\{5,13\}$. The reverted $a$-phase is seen at the edge and in the middle as lamellate, as marked in the micrographs. The dark lield image was obtained using the (1013) reflection of the $\alpha$-phase and, hence, the reverted $\alpha$-lamellate in the $\omega$-phase are lit up. A dense dislocation network is seen in the $\omega$-phase and its 

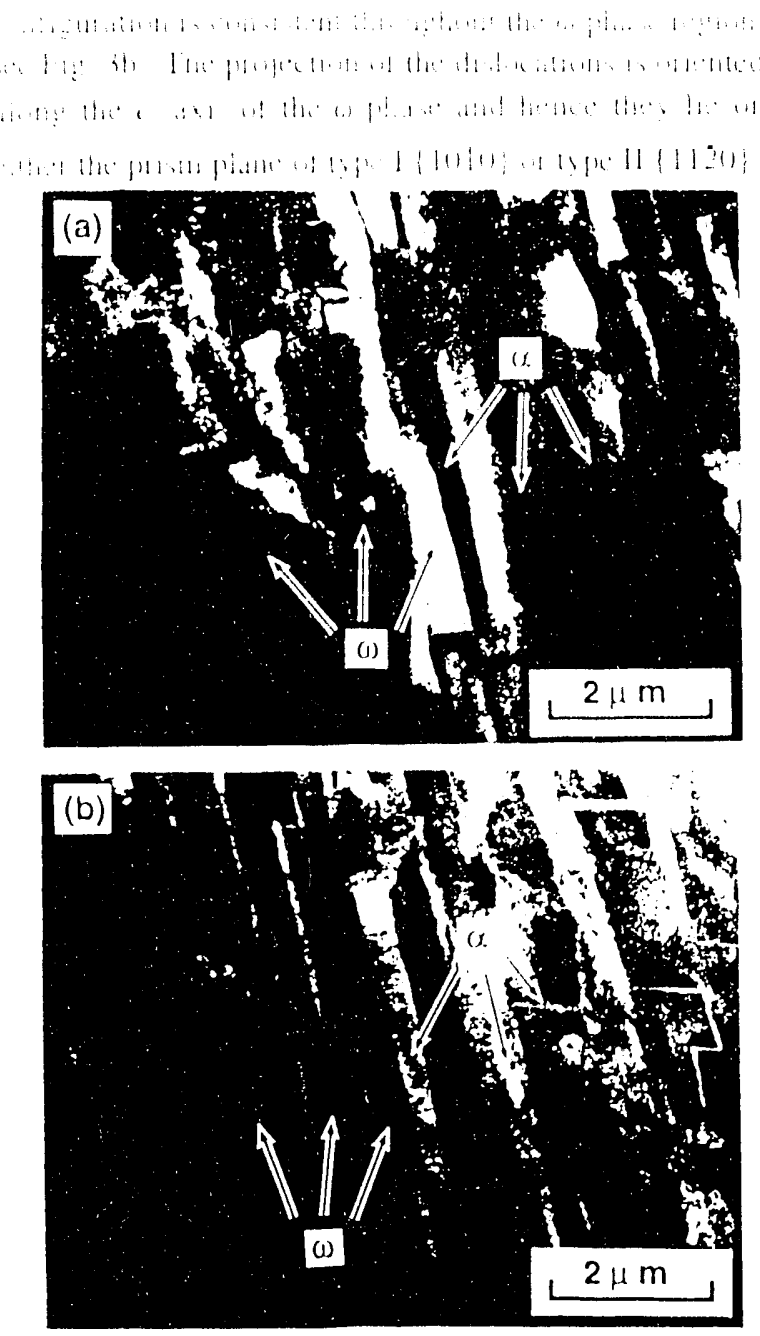

Hegre 3 Relained (s)-phase and reverted (x-phase in a bught licld (a) and a dark field mage (b).

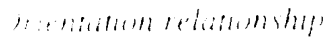

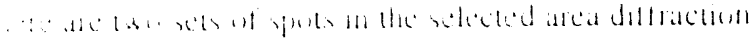

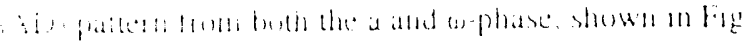

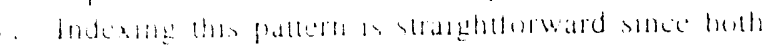

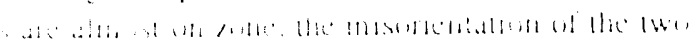

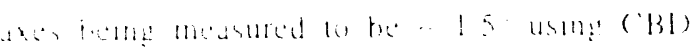

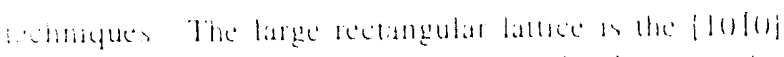

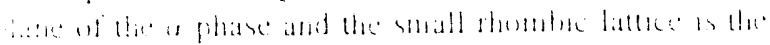

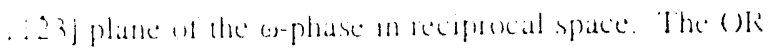

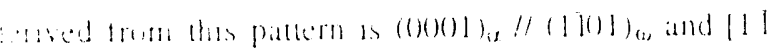

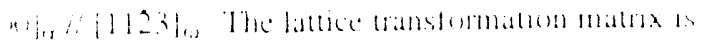

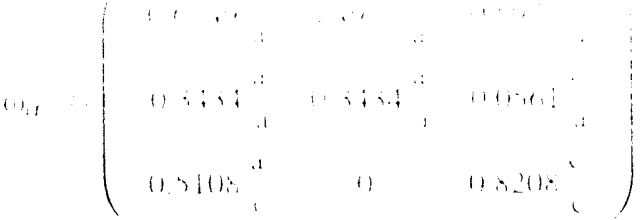

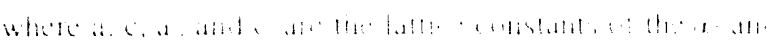

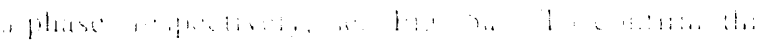

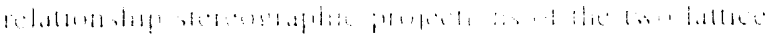

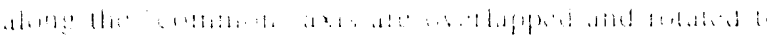

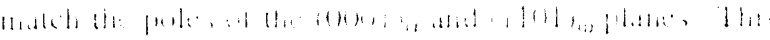

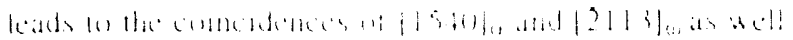

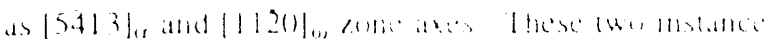

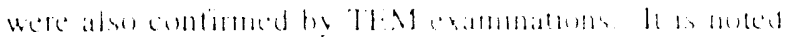

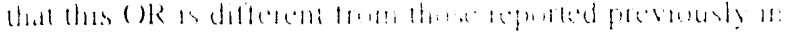

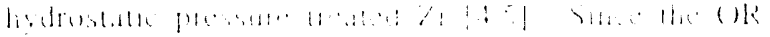

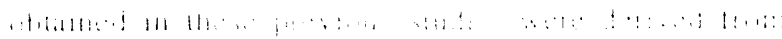

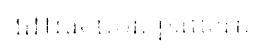

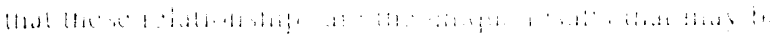

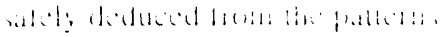

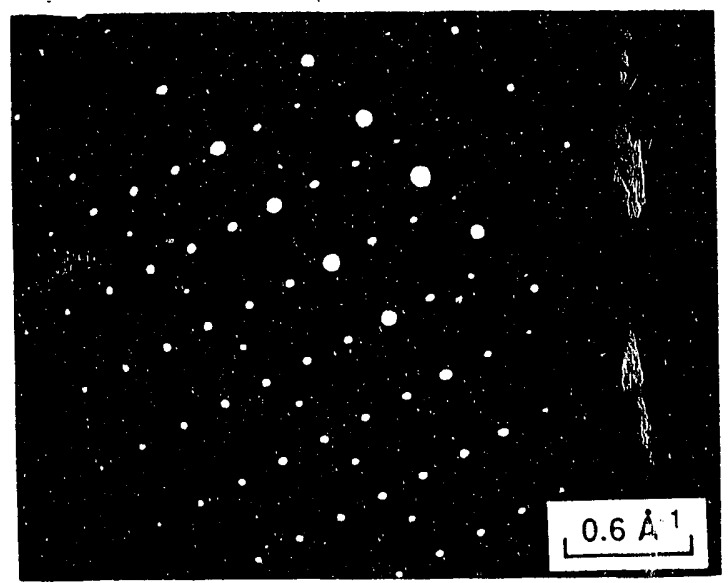

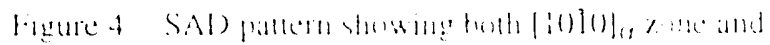
$11123\}_{10} 21110 \times 1 \times 20$

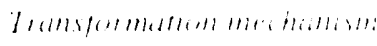

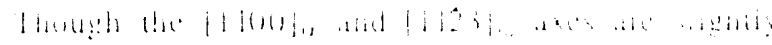

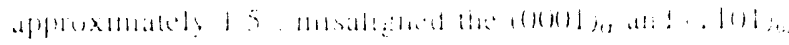

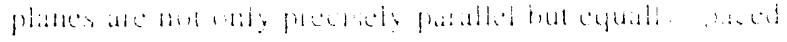

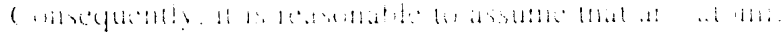

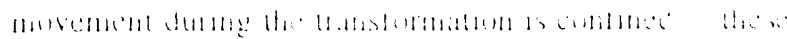

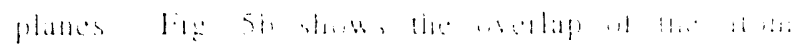

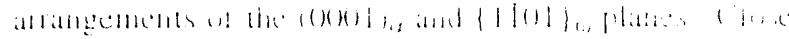


examination of the atomic positions before and after the transformation shows that the lattice reconstruction can be accomplished principally by simple shearing in and hewween the planes, in agreement with the assumption above. The shear component along the $[1101]_{\omega}$ direction is about $14 \%$ and along the $[1123]_{\omega}$ is only $3 \%$. The latter corresponds to an approximately $2^{\circ}$ misorientation between the $[1100]_{\alpha}$ and $[1123\}_{\omega}$ axes, which is consistent with the experimentally measured value. It can be seen from Fig. $5 b$ that the relative atomic movement required for the lattice reconstruction is quite small and, thus, the nearest neighbors remain the same and shortrange order is retained. The characteristics of this transformation are the same as those of a martensitic transiormation, so it is considered to be a martensitic iype.

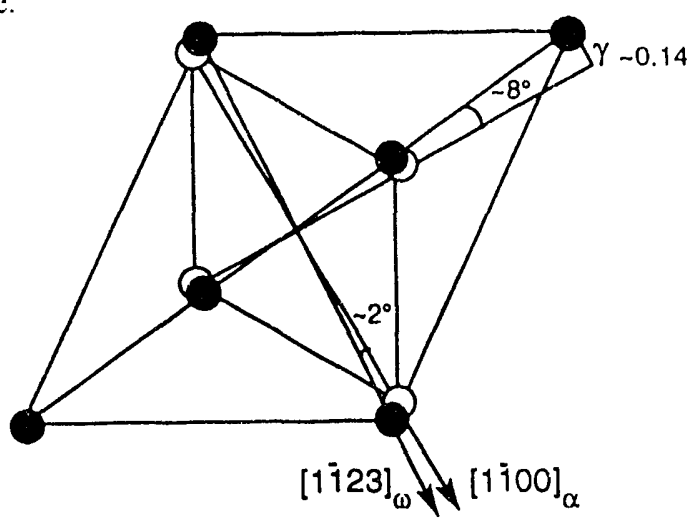

Figure 5 Alomic arrangements of the two lattices in the parallel planes.

It is well known that the introduction of internal structures such as dislocations and twins is an integral part of the martensitic transformation, compensating for the distortion caused by the lattice reconstruction and resulting in a macroscopically undistorted sample. Since shear is principally involved in the $\alpha \rightarrow \omega$ transformation, dislocations may be sufficient to compensate for the distortion resulting from the reconstruction. In fact, a very high density of dislocation networks was observed in the retained $\omega$-phase, see Fig. 3b, while twinning was not seen. The dislocations are of $c$ and $a$ type lying on the prism planes. Reverted $\alpha$-phase at the edge of and in the interior of the retained $\omega$-phase can be seen as well. Since there are eight possible variants of the reverted $\alpha$-phase in the interior, lamellae of differently oriented $\alpha$-phase lamellae are readily seen in Fig. 3.
Summary

The introduction of dislocation cell, twins, microbands, and $\omega$-phase during shock-loading significantly alters the mechanical response of $\mathrm{Zr}$ shockloaded to $7 \mathrm{GPa}$. The yield strength increases by about $60 \%$ and the work hardening rate at room temperature is considerably enhanced.

The $\alpha \rightarrow \omega$ transformation resulting from shock loading was detected and the retained $\omega$-phase was observed. The transformation is of martensitic type and the lattice reconstruction is accomplished, in principle, through shearing that is contained on specilic planes. The OR observed is determined to be $(0()(1) 1)_{\alpha} / /(1101)_{\omega}$ and

$[1100]_{\alpha} / /[1123]_{\omega}$ which differs from those previously reported. A high density of dislocations was observed in the retained $\omega$-phase, which was necessary for compensating the distortion due to the lattice reconstruction. Variants of the reverted $\alpha$-lamellate were found in the incerior of the retained $\omega$-phase.

References

1 P. W. Bridgman, Proc. Am. Acad. Arr Sci. (1952), 81, 165.

2 J. C. Jamieson, Science, (1963), 140, 72.

3 G. A. Sargent and H. Conrad, Materials Sci. Eng. (1971), 7, 220.

4 M. P. Usikov and V. A. Zilhershtein, Phys. Stat. Sol. (1973), 19, 53.

5 A. Rabinkin, M. Talianker, and O. Botstein, Acta Metall. (1981), 29, 691 .

6 S. K. Sikka, Y. K. Vohra, and R. Chidambaram, Prog. in Mater. Sci. (1982), 27, 245.

7 G. T. Gray III, C. E. Morris, and A. C. Lawson, Proc. 7th Inter. Conf. on Ti, (1993), TMS, Pittsburgh, Pennsylvania, (in press).

8 G. T. Gray III, High Pressure Shock Compression of Solids, (edited by J. R. Asay and M.. Shahinpoor) Springer, Berlin. In Press.

9 F. D. Rosi, C. A. Dube and B. H. Alexander, J. Metals, (1953), 5, 257.

10 E. J. Rappeiport, Acta Metall. (1959), 7, 254.

11 A. T. Churchman, Proc. Roy. Soc. (1954), A226, 216.

12 S. Song and G. T. Gray III, (1993), to be published.

13 B. Olinger and J. C. Jamieson, High Temp. High Pres. (1973), 5, 123. 

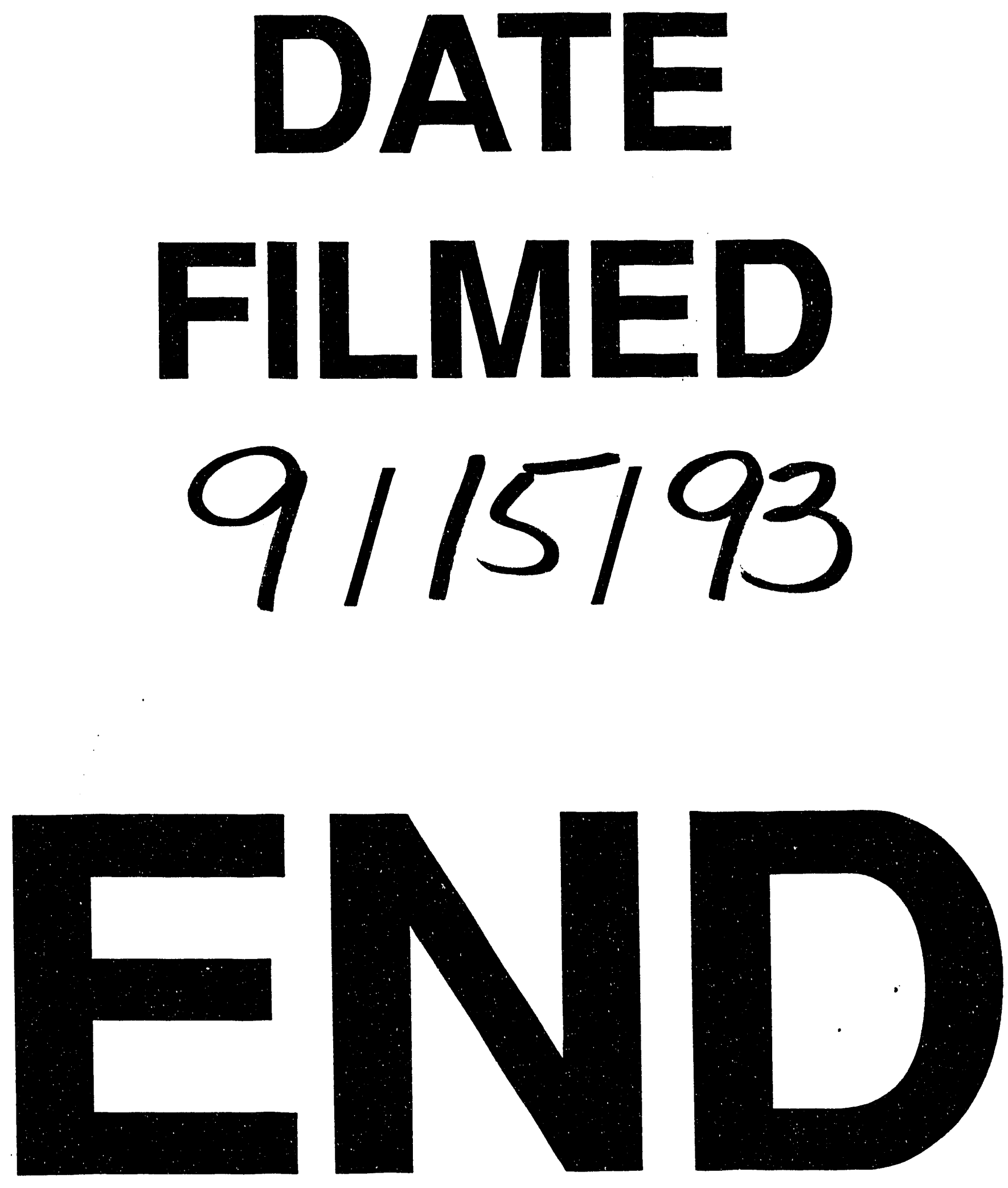
